\title{
A Therapeutic Connection between Migraine and Epilepsy
}

\section{Iraj Derakhshan*}

Cincinnati and Case Western Reserve and Cincinnati Universities, Ohio, USA

*Corresponding author: Iraj Derakhshan, Cincinnati and Case Western Reserve and Cincinnati Universities, Ohio, USA; Tel: 304 343 4098 ; Fax: 304 343 4598 ; E-mail: idneuro@hotmail.com

Received date: February 05, 2017; Accepted date: February 24, 2017; Published date: February 28, 2017

Copyright: @ 2017 Derakhshan I. This is an open-access article distributed under the terms of the Creative Commons Attribution License, which permits unrestricted use, distribution, and reproduction in any medium, provided the original author and source are credited.

\begin{abstract}
The connection between the episodic conditions, migraine and epilepsy, is widely acknowledged but the mechanism involved is subject to debates. Similarly, the role of maintenance opioid in preventing migraine and related entities is well known but few reports exist on the prophylactic use of opioids in preventing both migraine and epilepsy (migralepsy) proven refractory to the use of conventional anticonvulsants. Here, I provide details of a patient with refractory migralepsy who responded favourably to daily scheduled opioid, with eventual complete remission of headaches and seizures at a high dose of oxycodone.
\end{abstract}

Keywords: Daily scheduled opioid; Refractory; Migralepsy; Maintenance

\section{Case Report}

Betty (not her real name) was first seen in 2007, at the age of 61 . She complained of headaches with features of migraine, backache and nocturnal numbness of upper extremities suggestive of carpal tunnel syndrome. The right sided headaches had started in 1999 and were associated with photophobia and nausea. Initially she was put on gabapentin, followed by valproate, without significant relief with either medication at significant doses. However, she responded to topiramate with significant relief in the severity of the headache although they continued to recur from time to time according to a headache diary she kept throughout her attendance to my office. Neurological examination and CT of brain were normal. Subsequently, the headaches improved on hydrocodone and triptans, in addition to topiramate. Eventually, however, she was put on daily scheduled opioid treatment for migraine using oxycodone. The dose was increased progressively for a complete relief from the headaches. She required increasing the dose gradually to $30 \mathrm{mg}, 2$ tablets three times daily. Surprisingly, it was at this high dose that not only the headaches stopped occurring but also the occasional seizures she suffered. The seizures she had experienced before usually occurred at the end of a prolonged migraine headache. I saw Betty accidentally in a social gathering wherein she recounted the return of her headaches and seizures because of her inability to find a physician willing to prescribe her the oxycodone. This case study, therefore, is similar to five other cases reported in a recent article; all achieving complete relief from both headache and epilepsy using the above-mentioned regimen.

\section{Review of the Literature}

The most striking clinical observation denoting a relationship between headache and epilepsy is a recent article by Shevel [1]. According to this report, a substantial reduction of seizures occurred in three patients with migraine following bilateral surgical closure of external carotid arteries performed for ameliorating the migraines. According to the author, the operation resulted in a significant reduction of the number of seizures in every case. In a similar vein, restoring the blood flow in the external carotid artery following widening of a significantly narrowed internal carotid artery, resulting in the resumption of normal blood flow in the ipsilateral external carotid artery, was followed by a significant reduction of headaches on that side [2].

The most pertinent statistical data concerning the frequency of the need for opioids in successfully preventing migraine and migrainerelated epilepsy (migralepsy) was published by Wilner et al. in 2016 [3-5]. Having identified epilepsy and migraine as comorbid conditions, the authors findings among 10, 271 patients with epilepsy, compared to that in 20,542 controls, indicated the need for prescription opioid in $26 \%$ of an insured population with epilepsy, versus $18 \%$ in a matched control population $(\mathrm{p}<0.001)$. Migraine occurred in $8 \%$ of the population with epilepsy and $2 \%$ of the controls $(p<0.001)$. The question asked by the authors was the driving force behind the need for prescribing opioids in those patients with epilepsy. The answer to that question was to be found in Table 1 of the article in question, i.e., increased prevalence of migraine and cervicalgia (a surrogate for migraine) in patients with epilepsy ( $28 \%$ vs. $10 \%$ among controls). A similar phenomenon had been observed by Verrotti et al. in another cohort of patients studied in Italy [6-8]. Thus, the common denominator in both of these large scale studies was the refractoriness of seizures to treatment by conventional antiepilepsy drugs alone, so long as the migraines were not fully controlled by a preventive medication. The role of maintenance opioid in achieving that goal was first documented by Miller in 1968 [9]. Recently, Derakhshan summarized later understandings concerning the topic [10]. Meanwhile, there are several other reports supporting the practice of daily scheduled opioid in treatment of refractory migraine as listed below [11-17].

Dedication and acknowledgement: I dedicate this article to the tender memories of my beloved sister (Farkhondeh) and mother (Rebecca) Derakhshan.

\section{References}

1. Shevel EI (2016) A report of three patients in whom the surgical closure of terminal branches of the external carotid arteries for treatment of 
Citation: Derakhshan I (2017) A Therapeutic Connection between Migraine and Epilepsy. J Neurol Neurophysiol 8: 414. doi:

Page 2 of 2

migraine resulted in significantly reduced frequency of epileptic attacks. $S$ Afr Med J 106: 1084-1085.

2. Herial NA, Khan AA, Thompson M, Suri MF, Qureshi AI ( 2014) Flowdiversion headaches in a patient with high-grade internal carotid artery stenosis. J Vasc Interv Neurol 7: 9-11.

3. Wilner AN, Sharma BK, Thompson AR, Krueger A (2016) Analgesic opioid use in a health-insured epilepsy population during 2012. Epilepsy Behav 57(PtA): 126-132.

4. Derakhshan I (2016) Analgesic opioid use in a health-insured epilepsy population during 2012: Consider migralepsy. Epilepsy Behav 60: 238.

5. Wilner AN, Sharma BK, Thompson AR, Krueger A (2016) Analgesic opioid use in a health-insured epilepsy population during 2012: Response to Derakhshan. Epilepsy Behav 60: 239.

6. Verrotti A, Laino D, Rinaldi VE, Suppiej A, Giordano L, et al (2016) Clinical dissection of childhood occipital epilepsy of Gastaut and prognostic implication. Eur J Neurol 23: 241-246.

7. Derakhshan I (2016) Hitting two birds with one stone: daily scheduled opioids in preventing migraine and migraine-related epilepsy (migralepsy). Eur J Neurol 2016 23: e58.

8. Verrotti A, Tambucci R, Striano P (2016) Reply to 'Hitting two birds with one stone: Daily scheduled opioids in preventing migraine and migrainerelated epilepsy (migralepsy)'. Eur J Neurol 23: e60-61.
9. Miller H (1968) Pain in the face. Br Med J 5605: 577-580.

10. Derakhshan I (2015) The diagnosis and treatment of chronic migraine: the case for daily scheduled opioid treatment in chronic headache. Ther Adv Chronic Dis 6: 389.

11. Hutchison R (2005) Opioids: The role in headache pharmacotherapy. J Opioid Manag 1: 193-194.

12. Finocchi C, Viani E (2013) Opioids can be useful in the treatment of headache. Neurol Sci 34 Suppl 1: S119-124.

13. Piekos K, Spierings EL (2009) Management of daily headache unresponsive to preventive treatment: Daily triptans versus daily opioids. Rev Neurol Dis 6: E121-130.

14. Ziegler DK (1997) Opioids in headache treatment. Is there a role? Neurol Clin 15: 199-207.

15. Sprenger T, Seifert CL, Miederer M, Valet M, Tölle TR (2008) Successful prophylactic treatment of chronic cluster headache with low-dose levomethadone. J Neurol 255: 1832-1833.

16. Bonezzi C, Demartini L (1999) Treatment options in postherpetic neuralgia. Acta Neurol Scand Suppl 173: 25-35; discussion 48-52.

17. Spierings EL, Volkerts ER, Heitland I, Thompson H (2014) A randomized, rater-blinded, crossover study of the effects of oxymorphone extended release, fed versus fasting, on cognitive performance as tested with CANTAB in opioid-tolerant subjects. Pain Med 15: 264-271. 